\title{
Analysis of emergency department length of stay for mental health visits: A case study of a Canadian academic hospital
}

\author{
Deyvison T. Baia Medeiros, BEng*; Shoshana Hahn-Goldberg, $\mathrm{PhD}^{\dagger}$; Erin $\mathrm{O}^{\prime}$ Connor, MD, $\mathrm{MSc}^{\ddagger}$; \\ Dionne M. Aleman, PhD, PEng*
}

\section{CLINICIAN'S CAPSULE}

What is known about the topic?

Little is available in Canadian literature regarding emergency department (ED) use by mental health patients.

What did this study ask?

Is the number of mental health visits to the ED increasing? Are there differences in ED length of stay between mental health and non-mental health visits?

What did this study find?

The number of mental health visits to the ED is increasing, and mental health patients experience longer wait times in the ED.

Why does this study matter to clinicians?

It informs clinicians who work with mental health patients of current ED demand trends and wait times for patients whom they see.

\section{ABSTRACT}

Objective: The objective of this study was to examine temporal trends in mental health visits to the emergency department (ED) and to determine differences in length of stay (LOS) between mental health visits and visits for nonmental health conditions.

Methods: A population-based retrospective study was conducted for patients who visited the ED of an academic hospital located in Toronto, ON, between fiscal years 2012 and 2016. Trends in the number of visits and descriptive statistics were calculated for both mental health and nonmental health groups. Quantile regression was used to compare the median and 90th percentile LOS.

Results: In five years, the absolute increase in the number of mental health visits to the ED was $55.7 \%$. The 90th percentile LOS was similar for mental and non-mental health visits that were internally transferred (10.7 hours v. 8.3 hours) but significantly higher for those who were discharged (11.4 hours v. 7.3 hours), admitted (52.6 hours v. 29.3 hours), and externally transferred (21.9 hours v. 10.0 hours). After adjusting for other variables, the 90th percentile LOS was 3.3 hours longer for mental health visits resulting in discharge $(p<0.001), 24.5$ hours longer for those admitted $(p<0.001)$, and 12.7 hours longer for those externally transferred $(p<0.001)$.

Conclusion: The number of mental health visits to the ED is linearly increasing over time, and the LOS in the ED is significantly longer for mental health visits for almost all discharge dispositions. Thus, systematic changes are needed to address the ED capacity to provide care for the growing mental health population.

\section{RÉSUMÉ}

Objectifs: L'étude visait à examiner les tendances temporelles des consultations au service des urgences (SU) pour des troubles mentaux, et à déterminer les différences de durée de séjour (DS) entre les consultations pour des troubles mentaux et celles pour d'autres types de troubles.

Méthode: II s'agit d'une étude rétrospective, fondée sur la population et menée chez des patients examinés dans un SU d'un hôpital d'enseignement à Toronto, entre les exercices 2012 et 2016. Les tendances relatives au nombre de consultations et des statistiques descriptives ont été calculées dans le groupe des troubles mentaux et dans celui d'autres types de troubles. Les comparaisons de la médiane et du $90^{\text {e }}$ centile de la DS ont été déterminées à l'aide de régressions quantiles.

Résultats: Le nombre de consultations au SU pour des troubles mentaux a augmenté en valeur absolue de 55,7\%, dans five ans. Quant au $90^{\mathrm{e}}$ centile de la DS au SU, il était comparable chez les patients mutés à l'interne, que ce soit pour des troubles mentaux ou pour d'autres types de troubles $(10,7 \mathrm{~h}$ contre [c.] 8,3 h); en revanche, il était significativement

From the *Department of Mechanical and Industrial Engineering, University of Toronto, Toronto, ON; †OpenLab, University Health Network, Toronto, ON; and ¥Division of Emergency Medicine, Department of Medicine, University of Toronto, University Health Network, Toronto, ON.

Correspondence to: Deyvison T. B. Medeiros, University of Toronto, 5 King's College Road, Toronto, ON M5S 3G8; Email: deyvison.baiamede iros@mail.utoronto.ca

A previous error has been corrected; please see DOI 10.1017/cem.2019.360.

(C) Canadian Association of Emergency Physicians CJEM 2019;21(3):374-383

DOI $10.1017 /$ cem.2018.417 
plus élevé chez les patients ayant quitté le service $(11,4 \mathrm{~h}$ c. $7,3 \mathrm{~h})$, chez ceux ayant été hospitalisés $(52,6 \mathrm{~h}$ c. $29,3 \mathrm{~h})$ ou chez ceux ayant été dirigés vers des services externes $(21,9 \mathrm{~h}$ c. 10,0 h). Après rajustement des données pour tenir compte d'autres variables, il s'est avéré que le $90^{\mathrm{e}}$ centile de la DS pour les consultations en santé mentale était plus long de $3,3 \mathrm{~h}$ dans les cas de congé du service $(p<0,001)$, de $24,5 \mathrm{~h}$ dans les cas d'hospitalisation $(p<0,001)$ et de $12,7 \mathrm{~h}$ dans les cas d'orientation vers des services externes $(p<0,001)$.

Conclusion: Le nombre de consultations pour des troubles mentaux au SU a connu une croissance linéaire au fil des ans et la DS y est significativement plus longue pour ce type de troubles que pour les autres, et ce, dans presque toutes les modalités de sortie du SU. Des changements relatifs au système s'imposent donc quant à la capacité de traitement, au SU, du nombre sans cesse croissant de patients atteints de troubles mentaux.

Keywords: Emergency department, length of stay, mental health, Canada

\section{INTRODUCTION}

It is estimated that $20 \%$ of Canadians, over 6.7 million people, experience a mental health or addiction problem. ${ }^{1}$ Projections show that, by the time Canadians reach 40 years old, 1 in 2 will have had or will have a mental illness. ${ }^{2}$ Despite these numbers and the increased attention that mental health has received in the media ${ }^{3,4}$ and in political discourse in recent years, ${ }^{3,5}$ Canada still has an underfunded and fragmented mental health system. ${ }^{6}$

Ideally, in the Canadian health system, diagnosis and treatment of mental health illnesses start in the community. Primary care providers (PCPs) should be the first professionals that people seek for help. ${ }^{7}$ After consultation with PCPs, patients may be referred for therapy or additional diagnosis with a specialist (e.g., psychiatrist) or access a variety of community services, including home care, and help lines. ${ }^{7}$ Emergency departments (EDs) should be used in crisis situations only. ${ }^{7}$ However, the lack of access to outpatient mental health services, such as PCPs, psychotherapy, or community services, drives people to seek care directly from the ED. ${ }^{6,8}$ In Ontario, for example, $44.6 \%$ of children and youth who visited the ED in 2014 for a mental health visit had no prior contact with any physician for that issue. ${ }^{9}$

Unlike in the United States where the medical literature has an extensive number of studies documenting trends in the use of EDs by mental health patients ${ }^{10-15}$ and the disproportional waits experienced by this population in the ED, ${ }^{16-20}$ there are very few studies in Canada. ${ }^{8,21-23}$ The Canadian studies are usually limited to a particular geographical area ${ }^{21}$ or population group, such as children ${ }^{8}$ and/or young adults. ${ }^{22}$ Moreover, the only Canadian article measuring length of stay (LOS) for patients with mental health conditions in the ED was published in 2012, using outdated data from $2009 .^{23}$
This study quantifies the impact of mental health visits to the ED of a single academic hospital that offers psychiatric emergency services and is located in Toronto, ON. In particular, this pilot study quantifies the incidence of visits to the ED and determines differences in LOS for patients with mental health visits versus those with visits for other reasons. This study also defines which sections of the ED visit have the largest impact on the overall LOS for mental health visits in the ED.

\section{METHODS}

\section{Toronto Western Hospital's ED}

The Toronto Western Hospital (TWH) is one of four academic hospitals comprising the University Health Network (UHN). ${ }^{24}$ It is a 272 -bed hospital, ${ }^{24}$ and its 34-bed ED treats more than 60,000 patients annually. ${ }^{24}$ TWH's Psychiatric Emergency Service Unit (PESU), where many mental health patients are directed upon arrival to the ED, is located physically adjacent to the ED. Initially implemented in 2005, the PESU is a safe and secure environment where up to six patients can stay at a time, for a maximum of 72 hours. ${ }^{25}$

Upon arrival to TWH's ED, patients proceed to registration/triage, where a nurse evaluates their condition and assigns an acuity score from 1 to 5 , with 1 being the most critical. Patients will then either be assigned to a bed where they wait to see a physician, or will remain in the waiting area until a bed becomes available. After a patient is seen by a physician, a lab or imaging tests may be ordered, and a consult with a specialist may be requested. Patients with tests or consults will wait for their results and then be reassessed by the ED physician. Patients are then discharged or transferred for admission. The process flow is depicted in Figure 1. 


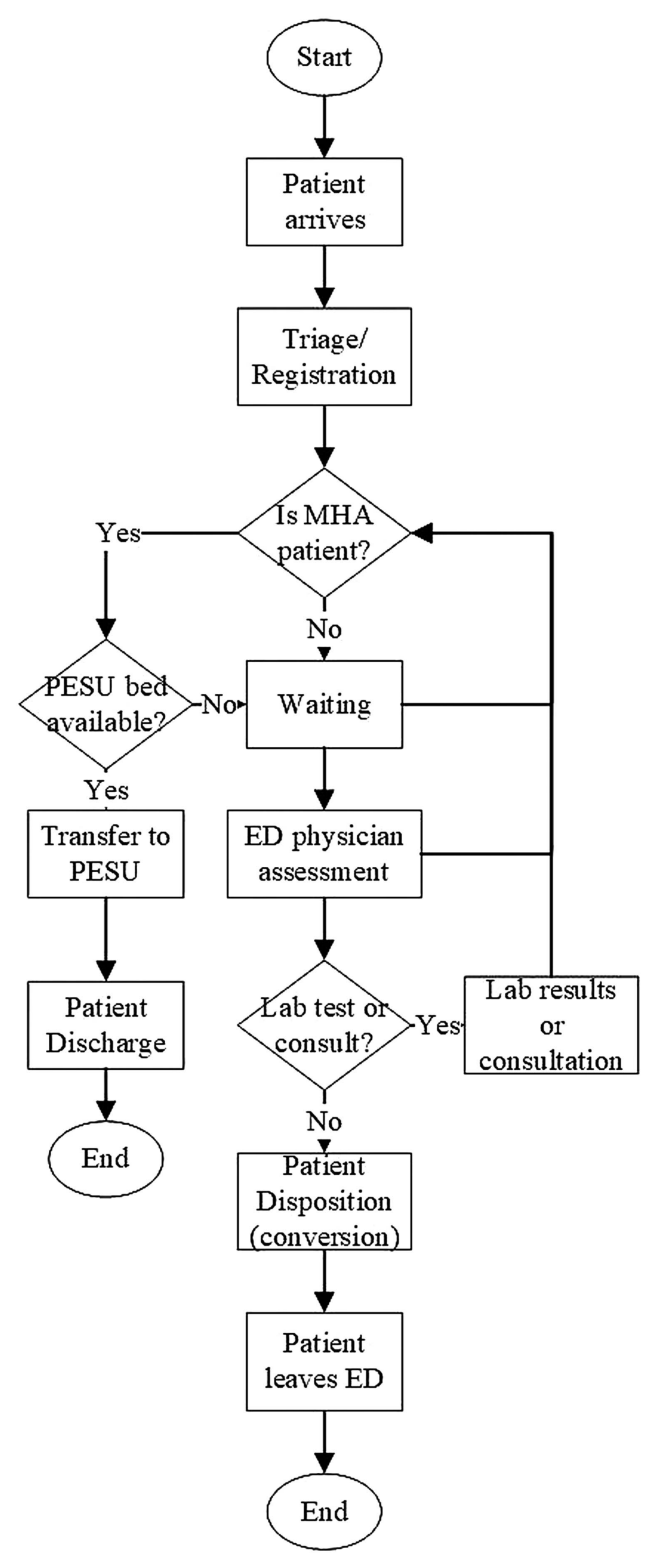

Figure 1. Process flow in the TWH ED.

If a patient presents to the ED with a mental health condition and there is a bed available in the PESU, he or she is automatically transferred there (i.e., internal transfer). Otherwise, the patient will occupy a regular bed in the ED until either a space in the PESU becomes available or until that patient is discharged from the ED (whichever one comes first).

\section{Study design and data source}

This retrospective study was conducted using data collected from the National Ambulatory Care Reporting System and the Electronic Patient Records (EPR) system from UHN. The study cohort includes all ED visits at TWH from April 2012 to March 2017, a total of five fiscal years (FY). Note that, a FY refers to the period from April 1 to March 31 of the following year.

The ED visits were grouped into two general categories (mental health and non-mental health), based on the International Statistical Classification of Diseases (ICD-10) associated with the Main Problem Code recorded for the visit. The mental health group included the following ICDs: Substance abuse (F55, F10F19), Schizophrenia (F20 - excluding F20.4, F21, F22, F23, F24, F25, F28, F29), Mood and affective disorder (F30, F31, F32, F33, F34, F39), Anxiety/Stress (F40, F41, F42, F43, F44, F45, F48), Adult personality and behavior disorders (F60, F63, F64, F65, F66, F68, F69), and Intentional self-harm (X60-X84). The non-mental health group included all other ICDs.

This study received ethics approval from the UHN Research Ethics Board.

\section{Measures of interest}

The four measures of interest were 1) time to physician initial assessment (PIA), 2) conversion time, 3) boarding time, and 4) total LOS. PIA is the time from registration to first assessment by a physician. Conversion time represents the time elapsed between PIA and the decision to admit the patient to the hospital (i.e., when the patient's status is changed to Admitted in the EPR). Time spent coordinating with consulting services (e.g., internal medicine, psychiatry) is counted in conversion time. Boarding time is the difference between the time when the admission happened (i.e., conversion time) and the time that the patient physically leaves the ED. Total LOS is the time from registration to the time when the patient physically leaves the ED.

To calculate these measures, visits were stratified into four mutually exclusive groups according to their discharge disposition: discharged, admitted, internal transfer, and external transfer. ${ }^{16}$ The discharged group comprised all visits that, after treatment in the ED, were discharged to the place of residence. The admitted group included all visits that resulted in an admission to a hospital ward, operating room, or critical care unit. Because TWH does not have inpatient psychiatric beds, whenever patients need to be admitted to a psychiatric unit, they are transferred within UHN to Toronto General Hospital (TGH), which is located $2.2 \mathrm{~km}$ from TWH. The internal transfer group comprised all visits 
that were transferred within the same hospital, usually to one of the clinics, day surgery, or within the $\mathrm{ED}$ (e.g., to the PESU). Finally, the external transfer group included all visits that were transferred to other acute or non-acute facilities (i.e., outside of UHN). PIA and total LOS were calculated for all four groups, whereas conversion time and boarding time were calculated for the admitted group only.

Although included in the computation of general descriptive statistics, visits with the discharge dispositions "left against medical advice" or "died upon arrival to ED" were excluded from the measures of interest. Moreover, because patients transferred to the PESU are described in the data as internal transfers, the time spent in the PESU does not count towards ED LOS reported in the results section.

\section{Statistical analysis}

Trends in the number of visits and general descriptive statistics were calculated for both mental health and non-mental health groups. The measures of interest are presented here as medians and 90th percentile values, and are stratified by mental health versus non-mental health visits and by discharge disposition (i.e., admitted, discharged, internal transfer, and external transfer).

Adjusted differences in wait times were evaluated using quantile regression, which is appropriate when distributions are right skewed and when there is an interest to assess differences in distributions quantiles (e.g., median or 90th percentile), rather than the usual differences in mean. ${ }^{26,27}$ Similar to the work presented, ${ }^{23}$ model covariates used in the adjusted model include acuity level (high or low), sex, time of the day, day of the week, and whether the patient arrived by ambulance.

The covariate acuity level refers to the score 1 to 5 given by a registered nurse when a patient presents to the ED according to the Canadian Triage and Acuity Scale (CTAS). ${ }^{28}$ In this study, CTAS scores of 1-3 are regarded as high acuity and 4-5 are low, similar to the targets for time spent in emergency rooms defined by the Ontario Ministry of Health and Long-Term Care. $^{29}$

Table 1. Baseline characteristics for mental health versus non-mental health visits

\begin{tabular}{|c|c|c|c|c|}
\hline & \multicolumn{2}{|c|}{ Mental health visits } & \multicolumn{2}{|c|}{ Non-mental health visits } \\
\hline & Absolute number & Weighted \% & Absolute number & Weighted \% \\
\hline Characteristic All visits & 24,972 & 100 & 283,044 & 100 \\
\hline Age & $N=24,906$ & & $N=282,999$ & \\
\hline$\leq 17$ & 239 & 1.0 & 5,955 & 2.1 \\
\hline $18-44$ & 14,942 & 60.0 & 118,185 & 41.8 \\
\hline $45-64$ & 8,024 & 32.2 & 79,785 & 28.2 \\
\hline $65+$ & 1,701 & 6.8 & 79,7074 & 27.9 \\
\hline Sex & $N=24,954$ & & $N=282,959$ & \\
\hline Female & 11,312 & 45.3 & 144,340 & 51.0 \\
\hline Male & 13,642 & 54.7 & 138,619 & 49.0 \\
\hline Arrived by ambulance & $N=24,972$ & & $N=283,034$ & \\
\hline Yes & 11,781 & 47.2 & 66,065 & 23.3 \\
\hline No & 13,191 & 52.8 & 216,969 & 76.7 \\
\hline Acuity level & $N=22,289$ & & $N=276,105$ & \\
\hline High (1-3) & 20,704 & 92.9 & 216,305 & 78.3 \\
\hline Low (4-5) & 1,585 & 7.1 & 59,800 & 21.7 \\
\hline Discharge disposition & $N=24,971$ & & $N=283,043$ & \\
\hline Discharged & 19,306 & 77.3 & 222,937 & 78.8 \\
\hline Admitted & 1,224 & 4.9 & 39,741 & 14.0 \\
\hline $\begin{array}{l}\text { Internal } \\
\text { transfer }\end{array}$ & 2,916 & 11.7 & 6,532 & 2.3 \\
\hline $\begin{array}{l}\text { External } \\
\text { transfer }\end{array}$ & 495 & 2.0 & 1,449 & 0.5 \\
\hline Left against medical advice or died & 1,030 & 4.1 & 12,384 & 4.4 \\
\hline
\end{tabular}




\section{RESULTS}

TWH received a total of 308,016 ED visits in 5 years, $24,972(8.1 \%)$ due to mental health conditions, and $283,044(91.9 \%)$ for any other non-mental health reason (Table 1). Mental health patients were more likely to be younger $(6.8 \%$ being $65+$ years old versus $27.9 \%)$, to be male $(54.7 \%$ versus $49.0 \%)$, to arrive by ambulance $(47.2 \%$ versus $23.3 \%$ ), and to receive higher acuity scores $(92.9 \%$ in the high acuity group versus $78.3 \%)$. Although mental health patients were more likely to be internally transferred (11.7\% versus $2.3 \%)$, they were less frequently admitted $(4.9 \%$ versus $14.0 \%)$.

The total number of ED visits increased linearly by $15.5 \%$ in 5 years from 56,345 to 65,078 . In the mental health group, the number of visits rose from 3,903 to 6,076 visits $(55.7 \%$ increase), whereas, in the nonmental health group, visits increased from 52,422 to 59,002 (14.5\% increase) (Figure 2). As of FY 2016, mental health related visits accounted for $9.3 \%$ of all ED visits at TWH. The slope for the mental health group linear trend was 420.3 with a mean squared error (MSE) of 120,959.3; the trend slope for the non-mental health group was 1,811.1 and MSE of 776,485.3. While the non-mental group demonstrated a consistent linear increase, the mental health group experienced some fluctuations, despite the overall increasing trend.

Considering the 90th percentile adjusted difference for patients that were discharged from the ED, mental health patients had longer wait times for both PIA ( 0.1 hour) and total LOS (3.3 hours) when compared to the non-mental health group (Table 2). Median values

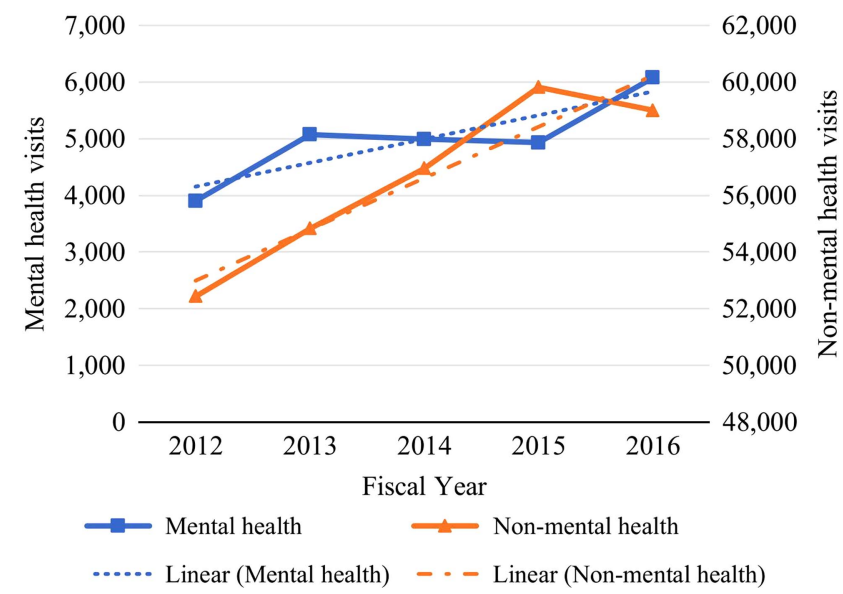

Figure 2. Trend in the number of mental and non-mental health visits to the ED. of the adjusted difference showed that mental health patients had similar wait times to see a physician, but they waited a 0.4 hour longer in total LOS than the non-mental health group patients.

The 90th percentile adjusted difference for the admitted group showed that mental health patients waited longer than other patients in all four metrics of interest (Table 3): time to PIA was a 0.1 hour higher (non-significant, $p>0.05$ ), conversion time was 8.4 hours higher, boarding time was 22.0 hours higher, and total LOS was 24.5 hours higher. Median values of the adjusted difference showed that mental health patients waited longer in only two of the measures of interest: conversion time was 3.1 hours higher and total LOS was 5.9 hours higher. In contrast, mental health patients experienced similar median wait times for PIA and a 0.8 hour shorter boarding time when compared to non-mental health patients.

Among the internally transferred group, the 90th percentile adjusted differences displayed non-significant results for both PIA (0.2 hour, $p>0.05)$ and total LOS (1.8 hours, $p>0.05$ ) (Table 4). Conversely, adjusted differences in median values showed that mental health patients waited a 0.3 hour less than other patients to be assessed by a physician and waited 2.9 hours less to physically leave the ED. Note that PIA and total LOS data were properly recorded for only a small portion of this specific group because most internal transfers happen upon arrival to the $\mathrm{ED}$, before any information is recorded in the EPR.

\begin{tabular}{|c|c|c|c|c|}
\hline & \multicolumn{2}{|c|}{ Visit type } & \multicolumn{2}{|c|}{ Difference } \\
\hline & $\begin{array}{c}\text { Mental } \\
\text { health } \\
(\mathrm{N}=19,306)\end{array}$ & $\begin{array}{c}\text { Non-mental } \\
\text { health } \\
(\mathrm{N}=222,937)\end{array}$ & $\begin{array}{c}\text { Non- } \\
\text { adjusted }\end{array}$ & Adjusted \\
\hline PIA & $N=17,979$ & $N=214,998$ & & \\
\hline Median & 1.5 & 1.5 & $\begin{array}{c}-0.1 \\
(p<0.001)\end{array}$ & $\begin{array}{c}0.0 \\
(p=0.13)\end{array}$ \\
\hline $90 \%$ & 3.2 & 3.2 & $\begin{array}{c}0.1 \\
(p<0.001)\end{array}$ & $\begin{array}{c}0.1 \\
(p<0.001)\end{array}$ \\
\hline $\begin{array}{l}\text { Total } \\
\text { LOS }\end{array}$ & $N=19,169$ & $N=222,850$ & & \\
\hline Median & 4.2 & 3.4 & $\begin{array}{c}0.8 \\
(p<0.001)\end{array}$ & $\begin{array}{c}0.4 \\
(p<0.001)\end{array}$ \\
\hline $90 \%$ & 11.4 & 7.3 & $\begin{array}{c}4.1 \\
(p<0.001)\end{array}$ & $\begin{array}{c}3.3 \\
(p<0.001)\end{array}$ \\
\hline
\end{tabular}


Table 3. Measures of interest, in hours, for admitted visits $(N=40,965)$

\begin{tabular}{|c|c|c|c|c|}
\hline & \multicolumn{2}{|c|}{ Visit type } & \multicolumn{2}{|c|}{ Difference } \\
\hline & $\begin{array}{l}\text { Mental health } \\
(\mathrm{N}=1,224)\end{array}$ & $\begin{array}{l}\text { Non-mental health } \\
\qquad(\mathrm{N}=39,741)\end{array}$ & Non-adjusted & Adjusted \\
\hline PIA & $N=999$ & $N=36,954$ & & \\
\hline Median & 1.4 & 1.4 & $\begin{array}{c}0.0 \\
(p=0.81)\end{array}$ & $\begin{array}{c}0.0 \\
(p=0.67)\end{array}$ \\
\hline $90 \%$ & 3.4 & 3.3 & $\begin{array}{c}0.1 \\
(p=0.30)\end{array}$ & $\begin{array}{c}0.1 \\
(p=0.43)\end{array}$ \\
\hline Conversion time & $N=999$ & $N=36,944$ & & \\
\hline Median & 8.3 & 5.3 & $\begin{array}{c}2.9 \\
(p<0.001)\end{array}$ & $\begin{array}{c}3.1 \\
(p<0.001)\end{array}$ \\
\hline $90 \%$ & 19.1 & 10.9 & $\begin{array}{c}8.2 \\
(p<0.001)\end{array}$ & $\begin{array}{c}8.4 \\
(p<0.001)\end{array}$ \\
\hline Boarding time & $N=999$ & $N=36,942$ & & \\
\hline Median & 2.9 & 4.2 & $\begin{array}{c}-1.3 \\
(p<0.001)\end{array}$ & $\begin{array}{c}-0.8 \\
(p<0.01)\end{array}$ \\
\hline $90 \%$ & 41.7 & 21.4 & $\begin{array}{c}21.1 \\
(p<0.01)\end{array}$ & $\begin{array}{c}22.0 \\
(p<0.001)\end{array}$ \\
\hline Total LOS & $N=1,213$ & $N=39,737$ & & \\
\hline Median & 18.0 & 12.6 & $\begin{array}{c}5.4 \\
(p<0.001)\end{array}$ & $\begin{array}{c}5.9 \\
(p<0.001)\end{array}$ \\
\hline $90 \%$ & 52.6 & 29.3 & $\begin{array}{c}23.4 \\
(p<0.001)\end{array}$ & $\begin{array}{c}24.5 \\
(p<0.001)\end{array}$ \\
\hline
\end{tabular}

\begin{tabular}{|c|c|c|c|c|}
\hline & \multicolumn{2}{|c|}{ Visit type } & \multicolumn{2}{|c|}{ Difference } \\
\hline & $\begin{array}{c}\text { Mental } \\
\text { health } \\
(\mathrm{N}=2,916)\end{array}$ & $\begin{array}{c}\text { Non-mental } \\
\text { health } \\
(\mathrm{N}=6,532)\end{array}$ & $\begin{array}{c}\text { Non- } \\
\text { adjusted }\end{array}$ & Adjusted \\
\hline PIA & $N=181$ & $N=1008$ & & \\
\hline Median & 1.1 & 1.6 & $\begin{array}{c}-0.5 \\
(p<0.001)\end{array}$ & $\begin{array}{c}-0.3 \\
(p<0.001)\end{array}$ \\
\hline $90 \%$ & 3.2 & 3.1 & $\begin{array}{c}0.1 \\
(p=0.67)\end{array}$ & $\begin{array}{c}0.2 \\
(p=0.42)\end{array}$ \\
\hline $\begin{array}{l}\text { Total } \\
\text { LOS }\end{array}$ & $N=397$ & $N=1,186$ & & \\
\hline Median & 0.5 & 3.5 & $\begin{array}{c}-3.0 \\
(p<0.001)\end{array}$ & $\begin{array}{c}-2.9 \\
(p<0.001)\end{array}$ \\
\hline $90 \%$ & 10.7 & 8.3 & $\begin{array}{c}2.6 \\
(p<0.05)\end{array}$ & $\begin{array}{c}1.8 \\
(p=0.10)\end{array}$ \\
\hline
\end{tabular}

For the externally transferred group, the 90th percentile adjusted difference showed that mental health patients had similar wait times for PIA when compared to the non-mental health group patients;

\begin{tabular}{|c|c|c|c|c|}
\hline & \multicolumn{2}{|c|}{ Visit type } & \multicolumn{2}{|c|}{ Difference } \\
\hline & $\begin{array}{l}\text { Mental } \\
\text { health } \\
(\mathrm{N}=495)\end{array}$ & $\begin{array}{c}\text { Non-mental } \\
\text { health } \\
(\mathrm{N}=1,449)\end{array}$ & $\begin{array}{c}\text { Non- } \\
\text { adjusted }\end{array}$ & Adjusted \\
\hline PIA & $N=445$ & $N=1,151$ & & \\
\hline Median & 1.6 & 1.2 & $\begin{array}{c}0.5 \\
(p<0.001)\end{array}$ & $\begin{array}{c}0.4 \\
(p<0.001)\end{array}$ \\
\hline $90 \%$ & 3.2 & 3.1 & $\begin{array}{c}0.2 \\
(p=0.24)\end{array}$ & $\begin{array}{c}0.0 \\
(p=0.88)\end{array}$ \\
\hline $\begin{array}{l}\text { Total } \\
\text { LOS }\end{array}$ & $N=487$ & $N=1,808$ & & \\
\hline Median & 4.8 & 4.2 & $\begin{array}{c}0.6 \\
(p<0.05)\end{array}$ & $\begin{array}{c}0.7 \\
(p<0.01)\end{array}$ \\
\hline $90 \%$ & 21.9 & 10.0 & $\begin{array}{c}12.3 \\
(p<0.001)\end{array}$ & $\begin{array}{c}12.7 \\
(p<0.001)\end{array}$ \\
\hline
\end{tabular}

however, they waited 12.7 hours longer before getting transferred to the external facility (Table 5). If median values of the adjusted difference are considered, then there is an increase in both PIA 
(0.4 hour) and total LOS (0.7 hour) for mental health visits.

\section{DISCUSSION}

This study confirms that ED visits for mental health conditions at TWH have significantly longer wait times when compared to visits for non-mental health reasons. Except for patients that were internally transferred, the overall LOS for mental health visits was significantly longer than non-mental health visits regardless of the discharge disposition (i.e., discharged, admitted, or external transfer).

Similar to the results presented in this analysis, several other studies report that mental health patients experienced longer ED LOS when compared to the non-mental health cohort. ${ }^{16,30-32}$ Among visits leading to discharge, for instance, the total LOS for mental health patients at TWH is $56 \%$ longer than the nonmental health cohort (90th percentile of 11.4 hours versus 7.3 hours). Supporting this finding, an older but nationwide study from the United States reported that discharged mental health patients waited 2.5 hours longer (90th percentile) before discharge in 2011. ${ }^{16}$

Although mental health patients discharged from the ED experience longer wait times before getting an initial assessment by a physician, this difference is not clinically significant, and it seems that the higher LOS is mostly driven by factors other than the PIA time. Though these factors were not investigated in this analysis because of data limitations (specifically, the lack of time stamps detailing what happens to patients after the initial workup), the literature suggests that prolonged LOS for discharged mental health visits may be associated with a shortage of outpatient facilities and resources where patients can be referred for complementary therapy once they leave the ED. $8,16,22,30,33,34$ This shortage leads to prolonged discharge planning for mental health patients, which involves establishing linkages with these critical services. This is generally not needed when discharge planning for non-mental health conditions.

The clinically significant differences in LOS become apparent when patients are admitted. The 90th percentile total LOS for mental health patients being admitted to the hospital is $79.5 \%$ longer than nonmental health patients to receive an inpatient bed (52.6 hours versus 29.3 hours). Similarly, a case study from an academic ED in the United States ${ }^{17}$ reports admitted mental health patients waiting, on average, more than three times longer than admitted nonmental health patients before being transferred to an inpatient ward (18.2 hours versus 5.7 hours). In contrast, in 2011, another study ${ }^{16}$ showed that admitted mental health patients waited only 8 minutes longer (90th percentile) than admitted non-mental health patients before leaving the ED.

Among admitted visits, both conversion and boarding times expressively impact the overall LOS. Not only are patients with mental health conditions waiting significantly longer for an admission decision (90th percentile of 19.1 hours versus 10.9 hours), which could be caused by either emergency physicians taking longer to decide on patient management or delays in consult with attending psychiatrists, but also once patients are admitted, mental health patients are disproportionally boarding in the ED, which could be partially attributed to their need to be transferred to another hospital within the UHN (i.e., TGH). For perspective, in a 2013 position statement given by the Canadian Association of Emergency Physicians, the target boarding time is 90th percentile within 8 hours. ${ }^{35}$

Boarding time has been established as a major aggravating factor for delays in patient care. ${ }^{17-20,36,37}$ Besides worsening ED crowding, ${ }^{17,19,20,35}$ delaying treatment for other ED patients, ${ }^{19,20}$ and deteriorating clinical outcomes, ${ }^{17,19,21,37}$ boarding also consumes scarce ED resources (e.g., beds, staff). ${ }^{17,19,20}$ Among the four measures used by the Canadian Institute for Health Information to describe high quality care $^{38}$ (evidence-based, patient-centred, safe, and timely), at the very least, two dimensions (safety and timeliness of care) are impacted by prolonged LOS and boarding. Given that the overall number of mental health visits to $\mathrm{TWH}$ is increasing at a greater rate than the nonmental health visits, the longer boarding times and LOS in this patient population can be predicted to have an increasing impact on overall ED crowding.

When considering visits that lead to internal transfers, the PESU has yielded some positive results. Aside from diverting roughly $20 \%$ of the total mental health demand from the ED to a more appropriate and safe environment to care for patients experiencing a mental health crisis, the PESU also seems to shorten the median overall LOS for patients with mental health issues (median total LOS of a 0.5 hour as opposed to 3.5 hours in the non-mental health group). Although longer for the mental health population, the 90th 
percentile wait times for the internally transferred group show non-significant differences between the wait experienced by mental health and non-mental health visits.

Among external transfers, it can be concluded that even though mental health patients experienced similar waits to be assessed by a physician in comparison to non-mental health patients (90th percentile of 3.2 hours versus 3.1 hours), they wait considerably longer to be transferred to another facility (90th percentile of 21.9 hours versus 10.0 hours). Again, the increased waiting time for final discharge in this population contributes to ED crowding. In smaller scales, similar differences in wait time are also reported in the United States, where externally transferred mental health patients experienced 90th percentile LOS of 11.9 hours versus 7.4 hours in the non-mental health group. ${ }^{13}$ Although the use of psychiatric emergency services, such as the PESU, may help meet the needs of mental health patients who look for care in the emergency rooms, these services have yet to offset the current shortage of inpatient resources. ${ }^{16}$

Further, the number of mental health related ED visits at TWH has grown by $55.7 \%$ from FY 2012 to FY 2016, similar to other institutions. ${ }^{8,10,22}$ Thus, if the number of mental health visits keeps growing, which is expected given the upward trend observed in the past few years, the wait times for mental health patients are expected to deteriorate even further. Table 6 in Online Appendix A shows that the gaps in LOS between mental health and non-mental health visits have accentuated over time (FY 2012-2016).

A system-wide potential solution to reduce wait times in the ED is to invest in services that prevent patients from coming to the ED in the first place: primary and community care. ${ }^{16,33,36,37}$ The collaborative care model, a model initially developed for chronic disease management, has been applied in mental health care in several European countries. ${ }^{39}$ The model brings together primary care physicians, case managers, and mental health specialists, to develop care plans ${ }^{39}$ and diverts the attention from treating acute symptoms to primary care and prevention. The Schizophrenia Society of Ontario has also suggested the need to strengthen primary care by expanding the Family Health Care Team program to reduce ED wait times. ${ }^{33}$

Within the hospital, solutions to reduce long ED wait times could include adding more inpatient beds to facilitate the outflow of patients from the ED. ${ }^{16,33}$ The use of dedicated emergency psychiatric services is another alternative to alleviate some of the ED workload. ${ }^{16,33}$ Because TWH already has the PESU, the hospital could likely benefit from increasing the number of PESU beds available. The use of mathematical tools, such as discrete event-based simulation, could assist in evaluating these changes and their impacts on the ED LOS.

Limitations of this study include the use of data from one ED only, potentially limiting the generalizability of the findings. However, it is important to note that several other urban hospitals in the Greater Toronto Area have a similar model of care, including St. Michael's hospital, ${ }^{40}$ St. Joseph's Health Centre in Toronto, ${ }^{41}$ and St. Joseph's Healthcare Hamilton in Hamilton. ${ }^{42}$ Moreover, the majority of mental health patients seen at TWH's ED are not diverted to the PESU, so they follow the same process flow as they would in any other ED.

In retrospective studies like this (i.e., with large sample sizes), differences between clinical and statistical significance should also be addressed. It may be true that some of the wait times presented in this analysis may not be clinically relevant, despite showing statistical significance. However, as wait times increase, it becomes more likely that patient management and clinical outcomes will be negatively affected. Several authors describe the ED as a non-therapeutic environment for patients in mental distress ${ }^{4-45}$; especially for people feeling paranoid, psychotic, and suicidal, the noisy and frenetic environment in the ED can potentially escalate symptoms. ${ }^{43}$ Hence, not only long wait times may be detrimental to the safety of mental health patients, but also it may compromise the safety of those around them (e.g., staff and other patients).

\section{CONCLUSION}

Using FY 2012-2016 data from a large academic hospital in Toronto, we evaluated the trends in ED visits for mental health conditions, as well as the differences in LOS for mental health-related visits versus other non-mental health conditions. The number of mental health visits to the ED is increasing over time, with a $55.7 \%$ increase in the last 5 years. The ED lengths of stay were significantly longer for mental health visits that were discharged, admitted, or externally transferred to another facility. Among admitted patients, boarding time constitutes the longest portion of the 
overall LOS for mental health patients. The disproportionate waits experienced by mental health patients highlight the lack of ED capacity to care for this vulnerable population. Thus, both system-wide and organizational changes are needed to improve the ability to provide care for the growing mental health population.

Competing interests: None declared.

\section{REFERENCES}

1. Smetanin P, Stiff D, Briante C, et al. The life and economic impact of major mental illnesses in Canada: 2011 to 2041; 2011. Available at: https://www.mentalhealthcommission.ca/ English/media/3182 (accessed August 15, 2017).

2. Mental Health Commission of Canada. Making the case for investing in mental health in Canada; 2017. Available at: https://www.mentalhealthcommission.ca/English/media/ 3842 (accessed August 15, 2017).

3. Canadian Civil Liberties Association. The current state of mental health in Canada; 2017. Available at: https:/ccla.org/ current-state-mental-health-canada/ (accessed 15 August 2017).

4 da Silva M. Despite funding boost, advocates say Canada has a mental health crisis; 2017. Available at: https://now toronto.com/news/despite-funding-boost-advocates-saycanada-has-mental-health-crisis/ (accessed 15 August 2017).

5. Kirby MJL, Keon WJ. Out of the shadows at last: transforming mental health, mental illness and addiction services in Canada; 2006. Available at: http://publications.gc.ca/col lections/collection_2011/sen/yc17-0/YC17-0-391-2-1-eng. pdf (accessed 2 October 2017).

6. Mental Health Commission of Canada. Changing directions, changing lives: the mental health strategy for Canada; 2012. Available at: http://strategy.mentalhealthcommission. ca/pdf/strategy-images-en.pdf (accessed 15 August 2017).

7. Centre for Addiction and Mental Health. Challenges \& choices: finding mental health services in Ontario; 2003. Available at: http://www.camh.ca/en/education/Documents/ www.camh.net/Care_Treatment/Resources_clients_families_ friends/Challenges_and_Choices/challenges_choices2003. pdf.

8. Newton AS, Ali S, Johnson DW, et al. A 4-year review of pediatric mental health emergencies in Alberta. C7EM 2009;11:447-54 (accessed 15 August 2017).

9. Institute of Clinical Evaluation and Sciences (ICES). The mental health of children and youth in Ontario: 2017 scorecard; 2017. Available at: https://www.ices.on.ca/Pub lications/Atlases-and-Reports/2017/MHASEF (accessed 4 April 2018).
10. HCUP Nationwide Emergency Department Database (NEDS). Trends in emergency department visits involving mental and substance use disorders, 20062013; 2016. Available at: https://www.hcup-us.ahrq.gov/reports/stat briefs/sb2 16-Mental-Substance-Use-Disorder-ED-VisitTrends.pdf (accessed August 15, 2017).

11. Larkin GL, Claassen CA, Emond JA, et al. Trends in U.S. emergency department visits for mental health conditions, 1992 to 2001. Psychiatric services (Washington, DC) 2005;56:671-7.

12. Smith RP, Larkin GL, Southwick SM. Trends in U.S. emergency department visits for anxiety-related mental health conditions, 1992-2001. I Clinic Psychiatry 2008;69:286-94.

13. Hakenewerth A, Tintinalli J, Waller A, et al. Emergency department visits by patients with mental health disorders North Carolina, 2008-2010. Morb Mortal Week Rep 2013;62(23):469-72.

14. Grupp-Phelan J, Harman JS, Kelleher KJ. Trends in mental health and chronic condition visits by children presenting for care at U.S. emergency departments. Public Health Rep 2007;122:55-61.

15. Pittsenbarger ZE, Mannix R. Trends in pediatric visits to the emergency department for psychiatric illnesses. Acad Emerg Med 2014;21:25-30.

16. Zhu JM, Singhal A, Hsia RY. Emergency department length-of-stay for psychiatric visits was significantly longer than for nonpsychiatric visits, 2002-11. Health Affairs (Project Hope) 2016;35:1698-706.

17. Nicks BA, Manthey DM. The impact of psychiatric patient boarding in emergency departments. Emergency Medicine International 2012;2012:360308, doi:10.1155/2012/360308.

18. Alakeson V, Pande N, Ludwig M. A plan to reduce emergency room "boarding" of psychiatric patients. Health Affairs (Project Hope) 2010;29:1637-42.

19. Pearlmutter MD, Dwyer KH, Burke LG, et al. Analysis of emergency department length of stay for mental health patients at ten Massachusetts emergency departments. Ann Emerg Med 2017;70:193-202.e16.

20. Nolan JM, Fee C, Cooper BA, et al. Psychiatric boarding incidence, duration, and associated factors in United States emergency departments. 7 Emerg Nurs 2015;41:57-64.

21. Matsumoto CL, O'Driscoll T, Lawrance J, et al. A 5 year retrospective study of emergency department use in Northwest Ontario: a measure of mental health and addictions needs. CFEM 2017;19:381-5.

22. Gandhi S, Chiu M, Lam K, et al. Mental health service use among children and youth in Ontario: population-based trends over time. Can 7 Psychiatry 2016;61:119-24.

23. Atzema CL, Schull MJ, Kurdyak P, et al. Wait times in the emergency department for patients with mental illness. CMA7 2012;184:E969-76 (accessed 2 October 2017).

24. University Health Network. Toronto Western Hospital; Available at: http://www.uhn.ca/corporate/AboutUHN/ OurHospitals/TWH (accessed 2 August 2017).

25. University Health Network. Psychiatric Services Unit: Welcome to the PESU; 2015. Available at: http://www.uhn. ca/PatientsFamilies/Health_Information/Health_Topics/ Documents/Psychiatric_Emergency_Services_Unit_PESU. pdf (accessed 15 August 2017). 
26. Ding R, McCarthy ML, Desmond JS, et al. Characterizing waiting room time, treatment time, and boarding time in the emergency department using quantile regression. Acad Emerg Med 2010;17:813-23.

27. Austin PC, Schull MJ. Quantile regression: a statistical tool for out-of-hospital research. Acad Emerg Med 2003;10:789-97.

28. Bullard MJ, Musgrave E, Warren D, et al. Revisions to the Canadian Emergency Department Triage and Acuity Scale (CTAS) Guidelines 2016. CFEM 2017;19:S18-27.

29. Ontario Ministry of Health and Long Term Care. Definitions: emergency room wait times; 2016. Available at: http:// www.ontariowaittimes.com/er/En/Definitions.aspx?view=1 (accessed 14 August 2017).

30. Weiss AP, Chang G, Rauch SL, et al. Patient and practicerelated determinants of emergency department length of stay for patients with psychiatric illness. Ann Emerg Med 2012;60:162-71.e5.

31. Stephens RJ, White SE, Cudnik M, Patterson ES. Factors associated with longer length of stay for mental health emergency department patients. 7 Emerg Med 2014;47:412-9.

32. Chang G, Weiss AP, Orav EJ, et al. Hospital variability in emergency department length of stay for adult patients receiving psychiatric consultation: a prospective study. Ann Emerg Med 2011;58:127-36.e1.

33. Schizophrenia Society of Ontario. Reducing emergency room wait times for people in psychiatric distress: recommendations from the Schizophrenia Society of Ontario; 2008. Available at: http://www.schizophrenia.on.ca/Policyand-Advocacy/Papers,-Submissions-Letters (accessed 17 August 2017).

34. Stone A, Rogers D, Kruckenberg S, Lieser A. Impact of the mental healthcare delivery system on California emergency departments. West 7 Emerg Med 012;13:51-6.

35. Affleck A, Parks P, Drummond A, et al. Emergency department overcrowding and access block. CFEM 2013;15:359-84.

36. Bender D, Pande N, Ludwig M. A literature review: psychiatric boarding; 2008. Available at: https://aspe.hhs.gov/ system/files/pdf/75751/PsyBdLR.pdf (accessed 14 August 2017).
37. American College of Emergency Physicians. Care of the psychiatric patient in the emergency department: a review of the literature; 2014. Available at: https://www.acep.org/ uploadedFiles/ACEP/Clinical_and_Practice_Management/ Resources/Mental_Health_and_Substance_Abuse/Psychia tric\%20Patient\%20Care\%20in\%20the\%20ED\%202014. pdf (accessed 2 October 2017).

38. Canadian Institute for Health Information. Quality of Care and Outcomes. Available at: https://www.cihi.ca/en/healthsystem-performance/quality-of-care-and-outcomes/qualityof-care (accessed 18 August 2017).

39. Evidence Exchange Network for Mental Health and Addictions (EEnet). Models of collaboration between primary care and mental health and substance use services; 2016. Available at: http://eenet.ca/sites/default/files/RapidReview_PC_MHA.pdf.

40. St. Michael's Hospital. Mental health and addiction services: psychiatric emergency services; . Available at: http://www. stmichaelshospital.com/programs/mentalhealth/emergency. php (accessed 4 April 2018).

41. St. Joseph's Health Centre. Mental health and crisis intervention; . Available at: https://stjoestoronto.ca/patient-careand-services/mental-health-crisis-intervention/ (accessed 4 April 2018).

42. St. Joseph's Healthcare Hamilton. Emergency psychiatric services; . Available at: https://www.stjoes.ca/hospital-services/men tal-health-addiction-services/mental-health-services/emergencypsychiatry-service (accessed 4 April 2018).

43. The College of Emergency Medicine. Mental health in emergency departments: a toolkit for improving care; 2013. Available at: https://www.rcpsych.ac.uk/pdf/CEM6883-Mental-Healthin-EDs-toolkit-(FINAL-FEB-2013)-rev1.pdf (accessed 2 October 2017).

44. Innes K, Morphet J, O'Brien AP, Munro I. Caring for the mental illness patient in emergency departments - an exploration of the issues from a healthcare provider perspective. 7 Clin Nurs 2013;23:2003-11.

45. Clarke DE, Dusome D, Hughes L. Emergency department from mental health client's perspective. Int 7 Mental Health Nurs 2006;16:126-31. 